\title{
Altruism and Pricing Strategy in Dual-Channel Supply Chains
}

\author{
Kuiran Shi, Feng Jiang, Qi Ouyang \\ College of Economics and Management, Nanjing University of Technology, Nanjing, China \\ Email: jfandfly@163.com, ouyangqihn@163.com, shikuiran@njut.edu.cn \\ Received May 1, 2013; revised June 1, 2013; accepted June 10, 2013
}

Copyright (C) 2013 Kuiran Shi et al. This is an open access article distributed under the Creative Commons Attribution License, which permits unrestricted use, distribution, and reproduction in any medium, provided the original work is properly cited.

\begin{abstract}
With the development of behavioral operational management, human behavior such as altruism, fairness and trust has received considerable attention. This paper studies the effect of altruism on retailer's and manufacturer's pricing strategy in two classic dual-channel supply chains by presenting Stackelberg game models. The analysis shows that the player's altruism preference strongly affects their pricing strategies. The more altruistic one player is, the more profits the other player obtains. Moreover, the effect of manufacturer's altruistic preference is larger than that of retailer's. In addition, online price is always lower than offline price in dual-channel supply chain, which still holds true considering altruism. The results also reveal that the product web-fit has significant effect on the player's optimal pricing strategies. The more compatible with online market the product is, the lower the retail price is set, and the more profit the manufacturer obtains whereas the less the retailer gets.
\end{abstract}

Keywords: Altruism; Dual-Channel Supply Chain; Pricing Strategy; Product Web-Fit

\section{Introduction}

With the emergence and development of internet, consumers' demand is increasing at an amazing speed, which opens an online market with great potential. According statistical data of iResearch, the amount of online shopping reached 498 billion in 2010, which is predicted to exceed 1000 billion in the year of 2013. Facing such temptation, every corporation is eager to share this "big cake" by adding an online channel besides the traditional one. According to one survey, about $42 \%$ of the top suppliers in a variety of industries such as IBM, Nike, Dell, Pioneer Electronics and Cisco System are selling directly to consumers through the direct online channel (see [1]). In addition, more and more retailers such as Wal-mart, Gome, Suning and Watsons also successfully opened their online market. In a word, e-commerce channel is increasingly adopted in supply chain. Dual-channel supply chain management is thus paid with high attention in recent years.

There are two main streams of research related to our paper, channel management in dual-channel supply chain and social preference. In the following, we briefly review the most related research and describe our contributions with respect to the vast, growing literature.

Contrary to tremendous interest in the dual-channel distribution strategy, much recent research on dual channel management tends to focus on pricing strategies rather than finding an optimal distribution strategy. Reference [1] shows that a direct online channel plays a role of exerting potential competition pressure on the existing retailer by increasing the manufacturer's negotiation power and reducing the double marginalization in the retail market even though its profit is non-positive. Reference [2] concludes that the manufacturer's optimal strategy is to charge the same price across both channels. [3] shows that an equal-pricing strategy-the online channel and the retail channel are priced the same-is appropriate as long as the retail channel is significantly more convenient than the Internet channel. [4] studies the optimal pricing strategy when a retailer sells its product through both the internet channel and the traditional channel. Reference [5] indicates that a manufacturer's contract with a wholesale price and a price for the direct channel can coordinate the dual-channel supply channel, benefiting the retailer but not the manufacturer. Reference [6] shows that the optimal pricing decisions are affected by customers' preference for the direct channel and the market scale, in both centralized and decentralized dual-channel supply chains. A lot of literature prove that dual-channel strategy is more preferable under most 
situation (see $[5,7,8])$. Retail services are taken into consideration in some literature, e.g. $[9,10]$.

There are other literature studied different factors affecting channel selection by supposing linear function of retailer's and manufacturer's effort in different channels. Reference [11] finds that channel preference depends on supply chain's efficiency and marketing capability. If the manufacturer is willing to reduce the wholesale price, both manufacturer and retailer can benefit from a dual channel. [12] indicates that the most critical factor in channel selection in a vertically integrated supply chain is the variable cost per unit of product sold using the direct vs. the retail channels. In the presence of independent retailer, the size of the retail-captive consumer segment relative to the size of the hybrid consumer segment becomes a major factor in channel selection. [13] investigates the impact of channel structures on the supplier, the retailer, and the entire supply chain in the context of two single-channel and two dual-channel supply chains.

Channel competition is always a hot point in dualchannel supply chain management. Reference [14] looks at price competition between the two channels using Bertrand and Stackelberg game models. [15] studies the impacts of different channel strategies on the total profits of a firm from a cooperative advertising perspective and showed that channel cooperation leads to an excess of profits that can be shared between the online and conventional parties. [16] studies the optimal contract design problem in a mixed channels supply chain considering information condition. [17] indicates that the manufacturer's optimal channel strategy depends on the channel environment. [18] examines the optimal decisions of delivery lead time and prices in centralized and decentralized dual-channel supply chains. In a Stackelberg model, [19] compares equilibrium price and profit of retail and manufacturer in different information conditions, information symmetry and asymmetry. Analysis of a bargaining model indicates that an information sharing equilibium can be reached by proper profit sharing. However, the above papers fail to address product webfit, which is well known for its strategic importance for online sales (see [20-22]). In our study, we incorporate product web-fit into our channel structure to study the pricing strategies in two classic dual-channel supply chains.

On the other hand, the development of behavioral operational management brings challenge to the "homo economics" hypothesis. Scholars show highly interest in the role of human behavior in management, which is the second literature stream related to our study. We only refer to the effect of social preference in supply chain management, which is the closest to this paper. For instance, Reference [23] proves that the fairness considera- tions can coordinate the channel under price-only contract. Assuming a linear demand function, [24] provides experimental evidence that there exist two contrasting social preferences that systematically affect economic decision making in supply chain transactions: while the relationship preference promotes cooperation, individual performance, high system efficiency, and sustainable over time, the status preference induces tough actions and reduces both system efficiency and individual performance. These authors find considerable support that the player's utility is a weighted linear function of each one's profit. In the context of SCM, References [25] and [26] discuss the effect of altruism on strategic behavior or partnership management. [27] shows that the performance of the supply chain in consideration of altruism is between those of scenarios under decentralization and under integration. The paper further point out that a manufacturer, as a leader, should find an egoistic retailer, while a retailer, as a follower, should find a manufacturer with altruistic liability, to form a good chain. Different from the above literature, this paper explores the effect of altruistic preference on each player's pricing strategy in two classic dual-channel supply chains.

Different channel selection leads to different supply chain structure. In a two-stage supply chain, according to which member use the dual-channel (traditional and online channel coexist), we have two classic dual-channel supply chain: retailer-dual channel manufacturersupply chain (supply chain (a)) and manufacturer-dual channel retailer-supply chain (supply chain (b)) (see Figure 1). Most of the literature about channel management

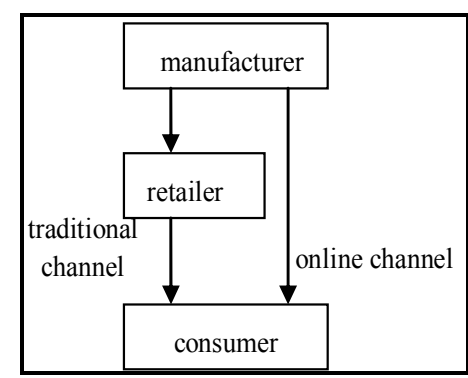

Supply chain (a)

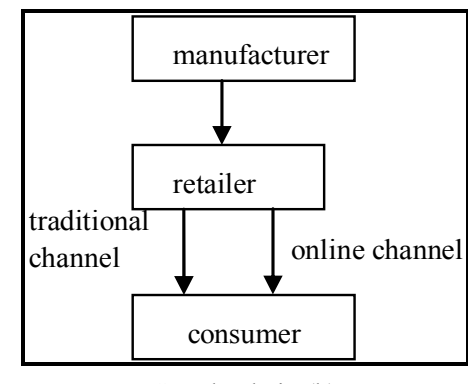

Supply chain (b)

Figure 1. Supply chain's structure of dual manufacturer and dual retailer. 
studied channel selection and price setting with respect to the manufacturer or the retailer. By comparing two classic dual-channel supply chains in the altruism and nonaltruism scenario, this paper tries to explore the effect of altruism on each player's pricing strategies. We incorporate product web-fit into demand function.

Reference [28] indicates that a product bought online is less valuable to the consumer than an identical product bought through a traditional retailer. There can be several reasons for this phenomenon. First, real product can be touched by consumers in physical stores, which well conveys product attributes, while online channel cannot. Second, for the online purchase, possession and gratification is delayed, whereas they are instant when the product is purchased through the traditional channel. Besides, consumers typically will be charged a transport fee for online purchases, and returns to online stores are difficult. All these factors reduce the value of the product for online purchases.

Suppose that the value of the product is $v$ when it is bought through traditional channel, and the value of the same product is $\theta v(\theta<1)$ when it is purchased online. The parameter $\theta$ is defined as product web-fit, and is determined by product attributes and the nature of online marketing. Based on empirical analysis of data, Reference [21] shows that product web-fit turns out to be less than one for most product categories (see Table 1). Therefore, product web-fit varies with product categories and the value of product web-fit ranges from zero to one $0<\theta<1$. The value of zero signifies that the product is not compatible with online marketing at all and the value of one signifies that the product is completely compatible with online sales. Our paper considers such products whose web-fit range from zero to one.

In this paper, we present an analytical framework for product web-fit in a centralized and a decentralized dual-channel supply chain system. In each system, we formulate Stackelberg game model to compare two classic dual-supply chains. In the decentralized system, altruism and non-altruism scenario are compared to exam the effect of altruism on pricing strategy. This paper contributes to the literature in the following three aspects: 1) we incorporate product web-fit in the demand function, which is more reasonable in fact; 2) we study the effect of altruism on each player's pricing strategies, a new perspective in dual-channel supply chain management; 3 ) two classic dual-channel supply chains are compared.

The reminder of this paper is organized as follows. Section 2 introduces the notation and formulates the decision models for the manufacturer and the retailer. In

Table 1. Product web-fit $\theta$ for web-based online channel.

\begin{tabular}{ccccccc}
\hline Category & Book & Shoes & Toothpaste & DVD player & Flower & Food items \\
\hline$\theta$ & 0.904 & 0.769 & 0.886 & 0.787 & 0.792 & 0.784 \\
\hline
\end{tabular}

Sections 3 and 4, we examine the price decisions of the retailer and the manufacturer in the non-altruism and altruism scenarios respectively. Section 5 gives numerical examples to illustrate the influence of altruism and product web-fit on the retailer's, the manufacturer's and whole supply chain's profits. We conclude the results and suggestions for future research in Section 6. All proofs are in the appendix.

\section{The Model}

In this paper, we consider a manufacturer who produces a single product at a unit $\operatorname{cost} c$ and distributes it through an independent retailer channel at a wholesale price $w$. The product is sold through online channel at price $p_{1}$ and through traditional channel at price $p_{2}$. Customers can choose either the traditional retail channel or the online channel to purchase the product.

We assume that in traditional channel consumers' evaluation of a product is $v$, and the retailer's price is $p_{2}$, then those consumers whose evaluation exceed $p_{2}$ would purchase the product through traditional channel as they can get surplus. $v_{r}$, which equals to $p_{2}$, is the marginal valuation for buying from the traditional channel. We therefore have the demand functiond $D=v-p_{2}$ when the retailer sales products only in physical stores.

Now we discuss mixed channel. Product web-fit needs to be considered. Consumers' evaluation of a product in online channel is supposed to be $\theta v$, and the product is sold online at the price of $p_{1}$, then consumers would prefer to buy the product from online channel if $\theta v>p_{1} v>$ $p_{1} / \theta$ as they can get surplus $\theta v-p_{1} \cdot v_{d}$, which equals $p_{1} / \theta$, is the marginal valuation for buying from the online channel. When facing two channels, consumers would prefer the channel which brings them more surpluses. So when

$$
\theta v-p_{1}>v-p_{2}, \quad\left(v<\frac{p_{2}-p_{1}}{1-\theta}\right)
$$

consumers would choose online channel. $v_{d r}$, which equals

$$
\frac{p_{2}-p_{1}}{1-\theta}
$$

is the marginal valuation for buying from traditional channel when comparing consumer surplus. When $v_{d}<v_{r}$, then $v_{d}<v_{r}<v_{d r}$, and those consumers whose evaluations are in the interval $\left[v_{d}, v_{d r}\right]$ would prefer to buy from the online channel, whose evaluations are in the interval $\left[v_{d r}, v\right]$ would prefer traditional channel. When $v_{d}>v_{r}$, then $v_{d}>v_{r}>v_{d r}$, and no consumers is willing to buy from the online channel as traditional channel would bring more surplus in comparison, those consumers whose evaluations are in the interval $\left[v_{r}, v\right]$ would prefer to buy from the traditional channel, but those whose 
evaluations are in the interval $\left[0, v_{r}\right]$ will not buy the product from either of the two channels. A similar market structure has been used by References [1] and [29]. Thus, the demand functions for the online and traditional channels, respectively, can be expressed as

$$
\begin{aligned}
& d_{1}=\frac{p_{2}-p_{1}}{1-\theta}-\frac{p_{1}}{\theta} \\
& d_{2}=v-\frac{p_{2}-p_{1}}{1-\theta}
\end{aligned}
$$

In supply chain (a), the retailer's and manufacturer's profits are determined by

$$
\begin{gathered}
\pi_{r}^{A}=\left(p_{2}-w\right) d_{2} \\
\pi_{m}^{A}=(w-c) d_{2}+\left(p_{1}-c\right) d_{1}
\end{gathered}
$$

In supply chain (b), the retailer's and manufacturer's profits are determined by

$$
\begin{gathered}
\pi_{r}^{B}=\left(p_{2}-w\right) d_{2}+\left(p_{1}-w\right) d_{1} \\
\pi_{m}^{B}=(w-c)\left(d_{1}+d_{2}\right)
\end{gathered}
$$

If the dual-channel supply chain is vertically integrated, then the profit of the centralized dual-supply chain (both supply chains (a) and (b)) is

$$
\pi_{c}=\left(p_{2}-c\right) d_{2}+\left(p_{1}-c\right) d_{1}
$$

Note that the formulations of supply chains (a) and (b)'s profits in centralized system are identical. The following section considers a centralized system in which all the decisions are centralized to maximize the performance of the entire supply chain, that is, the manufacturer is vertically integrated with the retailer. She controls both decisions: the retail price and direct sale price. The centralized system solution serves as a benchmark for the decentralized setting. Then we consider a decentralized supply chain under the Stackelberg game led by the manufacturer. For the decentralized situation, two supply chains ((a) and (b)) are compared in non-altruism and altruism scenarios respectively.

In supply chain (a), the decision process is assumed to follow the following sequence: the manufacturer, as the Stackelberg leader, determines the wholesale price and direct sale price first, then the retailer as the follower, sets his own retail price based on the manufacturer's decisions. Similarly, in supply chain (b), the manufacturer sets the wholesale price first, and the retailer decides the traditional and online retail price accordingly.

Here the subscript " $m$ ", " $r$ ", " $c$ " means the parameters corresponding to the manufacturer, the retailer and the wholesale system; the superscript " $c$ ", " $d$ ", " $A$ " and " $B$ " means the parameters corresponding to the centralized and decentralized system, supply chains (a) and (b). In supply chain (a), we call the online channel as the direct channel because the manufacturer sells products through online channel directly.

\section{Non-Altruism}

In this Section, we discuss the retailer's and manufacturer's price strategies when both of them are not altruistic.

\subsection{Centralized Dual-Channel Supply Chain Model}

The supply chain performs best if the channel is centrally controlled. Since the wholesale price is only used to divide the profit between the retailer and the manufacture, $w$ is no longer decision variable in the centralized supply chain. The decision variable is only $p_{1}, p_{2}$.

Substituting (1) and (2) into (7), we obtain:

$$
\pi_{c}=\left(p_{2}-c\right)\left(v-\frac{p_{2}-p_{1}}{1-\theta}\right)+\left(p_{1}-c\right)\left(\frac{p_{2}-p_{1}}{1-\theta}-\frac{p_{1}}{\theta}\right)
$$

Proposition 1. The online price and the traditional price are given by

$$
p_{1}^{c}=\frac{c+v \theta}{2}, p_{2}^{c}=\frac{c+v}{2},
$$

and the total profit $\pi_{c}$ is given as

$$
\pi_{c}=\frac{c^{2}+v^{2} \theta-2 c v \theta}{4 \theta} .
$$

We easily know $p_{1}^{c}$ and $p_{1}^{c}$ will increase with increasing $v$, which is reasonable because, intuitively, the higher the consumers' evaluation for a product is, the higher its price will be set. In addition, $p_{1}^{c}$ increase with increasing $\theta$ while $p_{1}^{c}$ is independent of $\theta$.

\subsection{Decentralized Dual-Channel Supply Chain Model}

In this Section, we discuss the decentralized system, in which the retailer and manufacturer maximize their own profits respectively. We model the decision process as a sequential, Stackelberg game, with the manufacturer as the leader and the retailer as the follower. We first give the retailer's and the manufacturer's best response functions, then present the method to decide the Stackelberg equilibrium strategies of the two players.

\subsubsection{Retailer-Dual Channel Manufacturer-Supply Chain}

Substituting (1) and (2) into (3) and (4), we obtain

$$
\begin{gathered}
\pi_{r}^{A}=\left(p_{2}-w\right)\left(v-\frac{p_{2}-p_{1}}{1-\theta}\right) \\
\pi_{m}^{A}=(w-c)\left(v-\frac{p_{2}-p_{1}}{1-\theta}\right)+\left(p_{1}-c\right)\left(\frac{p_{2}-p_{1}}{1-\theta}-\frac{p_{1}}{\theta}\right)
\end{gathered}
$$


Proposition 2. In retailer-dual channel manufacturersupply chain, the optimal price of manufacturer and retailer are given respectively by

$$
\begin{gathered}
p_{1}^{d A}=\frac{\theta v+c}{2}, w^{d A}=\frac{v+c}{2}, \\
p_{2}^{d A}=\frac{v}{2}+\frac{(3-\theta) v}{4} .
\end{gathered}
$$

The corresponding profits of manufacturer, retailer and total supply chain are given as

$$
\begin{gathered}
\pi_{m}^{A}=\frac{\theta v^{2}+\theta^{2} v^{2}+2 c^{2}-4 \theta v c}{8 \theta}, \pi_{r}^{A}=\frac{(1-\theta) v^{2}}{16}, \\
\pi_{c}^{A}=\frac{3 \theta v^{2}+\theta^{2} v^{2}+4 c^{2}-8 \theta v c}{16 \theta},
\end{gathered}
$$

respectively.

We can easily know that $p_{1}^{d A}, w^{d A}, p_{2}^{d A}$ all increase with increasing $v$, which is intuitively reasonable. $p_{1}^{d A}$ also increases with increasing $\theta$, while $p_{2}^{d A}$ decreases with increasing $\theta$, and $w^{d A}$ is independent of $\theta$. Proposition 2 indicates that in supply chain (a), the formulations of the optimal wholesale price and the optimal direct sale price are identical to the optimal traditional price and the online price in the centralized system. In other words, compared with the pricing strategies in the centralized supply chain, the manufacturer should consider the retailer as an end customer and set the wholesale price equal to the retail price in the centralized supply chain, and keep the direct sale price unchanged. Note that when $\theta$ is between 0 and $1, p_{1}^{d A}$ is always smaller than $w^{d A}$, which would render the retailer order his products through the online channel instead of the traditional channel. The extreme case is that the manufacturer sells all his products through the online channel.

\subsubsection{Manufacturer-Dual Channel Retailer-Supply Chain}

Substituting (1) and (2) into (5) and (6), we obtain

$$
\begin{array}{r}
\pi_{r}^{B}=\left(p_{2}-w\right)\left(v-\frac{p_{2}-p_{1}}{1-\theta}\right) \\
+\left(p_{1}-w\right)\left(\frac{p_{2}-p_{1}}{1-\theta}-\frac{p_{1}}{\theta}\right) \\
\pi_{m}^{B}=(w-c)\left(v-\frac{p_{1}}{\theta}\right)
\end{array}
$$

Proposition 3. In Manufacturer-dual channel retailersupply chain, the optimal price of manufacturer and retailer are given respectively by

$$
w^{d B}=\frac{c+\theta v}{2}, \quad p_{1}^{d B}=\frac{3 \theta v+c}{4}, \quad p_{2}^{d B}=\frac{2 v+c+\theta v}{4} .
$$

The corresponding profits of manufacturer, retailer and total supply chain are given as

$$
\begin{gathered}
\pi_{m}^{B}=\frac{c^{2}-2 c \theta v+\theta^{2} v^{2}}{8 \theta}, \pi_{r}^{B}=\frac{c^{2}-2 c \theta v+\theta v^{2}}{16 \theta}, \\
\pi_{c}^{B}=\frac{3 c^{2}-6 c \theta v+\theta v^{2}(1+2 \theta)}{16 \theta},
\end{gathered}
$$

respectively.

From Proposition 3, we see that $w^{d B}, p_{1}^{d B}, p_{2}^{d B}$ are all increasing functions to $v$ and $\theta$. Not that $\theta$ is between 0 and $1, p_{1}^{d B}$ is always smaller than $p_{2}^{d B}$, that means, the retailer sets a lower online price to appeal consumers into online market. Compared with supply chain (a), the manufacturer sets a smaller wholesale price in supply chain (b). A reasonable explanation is that when the retailer opens an online channel, the retailer benefits from dual-channel while whether the manufacturer's profit will be increased depends on the value of product web-fit. As a result, the manufacturer in supply chain $\mathrm{B}$ had better to reduce wholesale price, otherwise the retailer may contact another manufacturer to get lower wholesale price and higher profit.

\section{Altruism}

Instead of being purely self-interested, both the manufacturer and retailer share some mutual concerns about the well-being of the others. Using altruistic utility or the "reciprocity-free" formulation in Reference [30], verified in the experiments by [24], the retailer's utility function is:

$$
U_{r}=\pi_{r}+\eta_{r} \pi_{m}
$$

where the coefficient $\eta_{r} \in[0,1]$ measures the degree of altruistic preference of the retailer towards the manufacturer. If $\eta_{r}=0$, the retailer is purely competitive towards the manufacturer, conversely, if $\eta_{r}=1$, the retailer is fully cooperative with the manufacturer. The larger (less) $\eta_{r}$ is, the more cooperative (competitive) the retailer towards the manufacturer will be.

Similarly, the manufacturer's utility is

$$
U_{m}=\pi_{m}+\eta_{m} \pi_{r}
$$

where $\eta_{m} \in[0,1]$ is the manufacturer's altruistic preference. Note that the retailer's profit $\pi_{r}$ takes full account of the inventory risk while $\pi_{m}$ takes no inventory risk at all, therefore $U_{m}$ reflects the manufacture willingness to share part of the supply chain inventory risk, and $\eta_{m}$ characterizes the degree of this willingness.

\subsection{Retailer-Dual Channel Manufacturer-Supply Chain}

Substituting (9) and (10) into (13) and (14), we obtain: 


$$
\begin{gathered}
U_{r}^{A}=\left(p_{2}-w\right)\left(v-\frac{p_{2}-p_{1}}{1-\theta}\right)+\eta_{r}\left[(w-c)\left(v-\frac{p_{2}-p_{1}}{1-\theta}\right)+\left(p_{1}-c\right)\left(\frac{p_{2}-p_{1}}{1-\theta}-\frac{p_{1}}{\theta}\right)\right] \\
U_{m}^{A}=(w-c)\left(v-\frac{p_{2}-p_{1}}{1-\theta}\right)+\left(p_{1}-c\right)\left(\frac{p_{2}-p_{1}}{1-\theta}-\frac{p_{1}}{\theta}\right)+\eta_{m}\left(p_{2}-w\right)\left(v-\frac{p_{2}-p_{1}}{1-\theta}\right)
\end{gathered}
$$

Proposition 4. For given $w$ and $p_{1}$, the optimal pricing strategy of altruistic retailer is given by:

$$
\begin{gathered}
p_{2}^{A}=\frac{1}{2}\left(p_{1}+v+w+p_{1} \eta_{r}-w \eta_{r}-v \theta\right) . \\
p_{1}^{A}=\frac{c+v \theta}{2}, \quad w^{A}=\frac{c\left(\eta_{r}-1\right)\left(\eta_{m}-2+\eta_{r} \eta_{m}\right)-2 v \theta \eta_{r}+v\left[2+\eta_{m}\left(\theta-2+\eta_{r}^{2} \theta\right)\right]}{2\left(\eta_{r}-1\right)\left(\eta_{m}-2+\eta_{r} \eta_{m}\right)}
\end{gathered}
$$

Then substituting $p_{1}^{A}$ and $w^{A}$ into $p_{2}^{A}$, we get the retailer's best response:

$$
p_{2}^{A}=\frac{2 v \theta \eta_{r}+2 c\left(\eta_{m}+\eta_{r} \eta_{m}-2\right)+v \theta\left(\eta_{r}-1\right)\left(\eta_{m}+\eta_{r} \eta_{m}-2\right)-v\left[6+\theta+\eta_{r}\left(\theta \eta_{r}-2\right)\right]}{4\left(\eta_{m}+\eta_{r} \eta_{m}-2\right)}
$$

From Proposition 4, we know that the altruistic retailer's traditional price and the altruistic manufacturer's wholesale price both decrease with increasing $\theta$ in supply chain (a), while the retailer's retail price decreases with increasing $\theta$. That means, the more compatible with online market the product is, the more profitable for the manufacturer and less profitable for the retailer. In addition, both the manufacturer's optimal wholesale price and the retailer's retail price are affected by the altruism coefficient, but the manufacturer's direct price is independent of the altruism magnitude.

\subsection{Manufacturer-Dual Channel Retailer-Supply Chain}

Substituting (11) and (12) into (13) and (14), we obtain:

$$
\begin{gathered}
U_{r}^{B}=\left(p_{2}-w\right)\left(v-\frac{p_{2}-p_{1}}{1-\theta}\right)+\left(p_{1}-w\right)\left(\frac{p_{2}-p_{1}}{1-\theta}-\frac{p_{1}}{\theta}\right)+\eta_{r}(w-c)\left(v-\frac{p_{1}}{\theta}\right) \\
U_{m}^{B}=(w-c)\left(v-\frac{p_{1}}{\theta}\right)+\eta_{m}\left[\left(p_{2}-w\right)\left(v-\frac{p_{2}-p_{1}}{1-\theta}\right)+\left(p_{1}-w\right)\left(\frac{p_{2}-p_{1}}{1-\theta}-\frac{p_{1}}{\theta}\right)\right]
\end{gathered}
$$

Proposition 5. For given $w$, the optimal pricing strategy of altruistic retailer is given by

$$
p_{1}^{B}=\frac{1}{2}\left(w+c \eta_{r}-w \eta_{r}+v \theta\right), p_{2}^{B}=\frac{1}{2}\left(w+c \eta_{r}-w \eta_{r}+v\right) .
$$

Substituting $p_{1}^{B}$ and $p_{2}^{B}$ into (18) and taking the first order condition with respect to $w$, letting it to zero, we have:

$$
w^{B}=\frac{c-2 c \eta_{r}+c \eta_{r}^{2} \eta_{m}+v \theta-v \eta_{m} \theta}{\left(\eta_{r}-1\right)\left(\eta_{m}+\eta_{r} \eta_{m}-2\right)}
$$

which is the altruistic manufacturer's best response. Then substituting $w^{B}$ into $p_{1}^{B}$ and $p_{2}^{B}$, we get the altruistic retailer's best response:

$$
\begin{gathered}
p_{1}^{B}=\frac{v \theta \eta_{m}-c+v \theta\left(\eta_{m}+\eta_{r} \eta_{m}-3\right)+c \eta_{r}\left(\eta_{m}-c \eta_{r} \eta_{m}+\eta_{r} \eta_{m}\right)}{2\left(\eta_{m}+\eta_{r} \eta_{m}-2\right)} \\
p_{2}^{B}=\frac{v \theta \eta_{m}-c-v \theta+v\left(\eta_{m}+\eta_{r} \eta_{m}-2\right)+c \eta_{r}\left(\eta_{m}-c \eta_{r} \eta_{m}+\eta_{r} \eta_{m}\right)}{2\left(\eta_{m}+\eta_{r} \eta_{m}-2\right)}
\end{gathered}
$$

From Proposition 5, we know that the optimal wholesale price, traditional price and online price all increase with increasing $\theta$ in altruism scenario. Compared with supply chain (a), in supply chain (b), the retailer, who adopted dual channel, owns more power to control the traditional and online prices, which leads to the positive correlation between her profit and the product web-fit. In addition, the wholesale price, online price and traditional 
price are all influenced by the altruism coefficient.

\section{Numerical Examples}

The purpose of our numerical examples is to explore the effect of product web-fit and altruism magnitude on each player's strategies in dual-supply chain. The numerical examples will complement our analytical results and provide us with more managerial insights. The values we used for the various parameters in our numerical examples are shown in Table 2 . We vary some of the parameters in Table 2 to find their effects on the optimum strategies.

\subsection{Effect of Product Web-Fit, $\theta$}

The impacts of the product web-fit on each supply chain player's strategies under the various scenarios are shown in Figures 2 and 3.

In Figure 2, we observe that the traditional and online price in supply chain (b) both increase with increasing $\theta$, while in supply chain (a), the online price increases with increasing $\theta$, but the traditional price decreases when the product web-fit increases. This is to be expected because the retailer in supply chain (b) decides both the online and the traditional price, when the product is more

Table 2. Parameters values and range of values used in the numerical examples.

\begin{tabular}{cc}
\hline Parameters & Base values of values \\
\hline$c$ & 20 \\
$v$ & 100 \\
$\theta$ & $0.5(0-1)$ \\
$\eta_{r}$ & $0.5(0-1)$ \\
$\eta_{m}$ & $0.5(0-1)$ \\
\hline
\end{tabular}

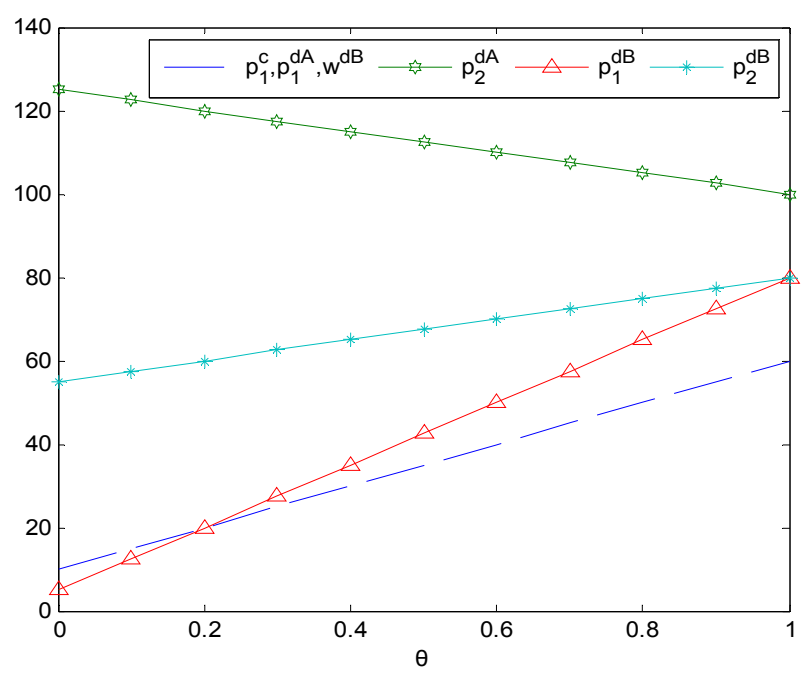

Figure 2. Impact of the product web-fit on each player's pricing strategy without altruism.

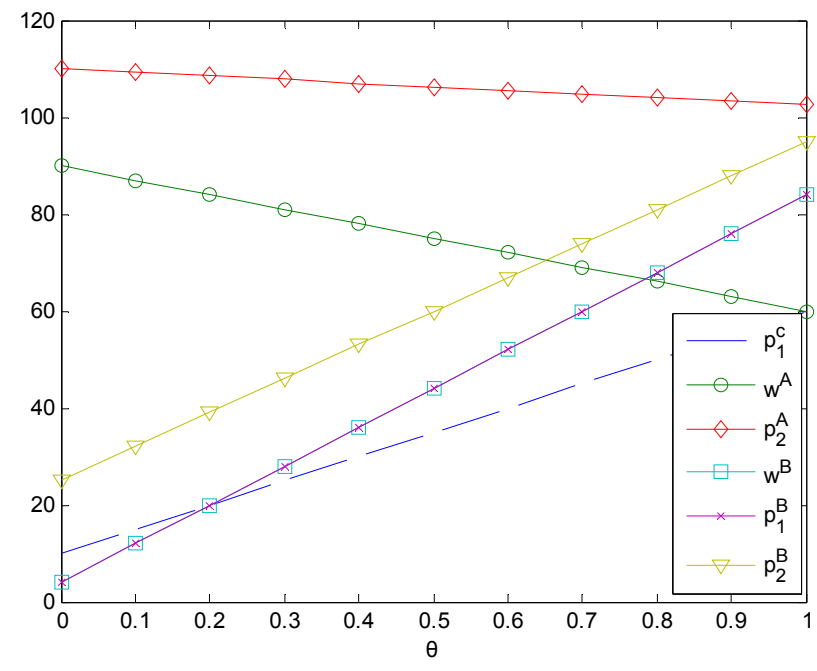

Figure 3. Impact of the product web-fit on each player's pricing strategy in altruistic scenario.

compatible with the online channel, the retailer benefits more from higher price. However, in supply chain (a), the retailer sets the retail price while the manufacturer decides the direct price for the same product, which brings competitive to the retailer and forces the retailer to reduce the retail price, and the more compatible with the online channel the product is, the lower the retail price is set. From Figure 2, we also know that the online price is always lower than the traditional price in both supply chain (a) and (b), which is intuitively because customers' evaluation for a product online is always lower than that in physical stores (see [28]).

Figure 3 illustrates the effect of the product web-fit on the altruistic retailer's and altruistic manufacturer's pricing strategies. We see some interesting changes compared with Figure 2. In supply chain (a), the retailer's traditional price and the manufacturer's wholesale price both decrease with increasing $\theta$, but the manufacturer's direct price increases with increasing $\theta$. That means, the more compatible with online market the product is, the more the manufacturer obtains but the less the retailer obtains. So the altruistic manufacturer will transfer some part of his profit to the retailer by reducing wholesale price when he considers the other player's welfare. In supply chain (b), wholesale price, traditional price and online price all increase with increasing $\theta$, and the manufacturer's wholesale price is so close to the retailer's online price, which makes the retailer obtain little profit from online channel, and the retailer would sale the product only through traditional channel in the long run. We also see that the online price is also lower than traditional price in both supply chains (a) and (b), just as in Figure 2.

\subsection{Effect of Altruistic Preference, $\eta_{r}, \eta_{m}$}

Figures 4 and 5 summarize the impacts of the altruistic 


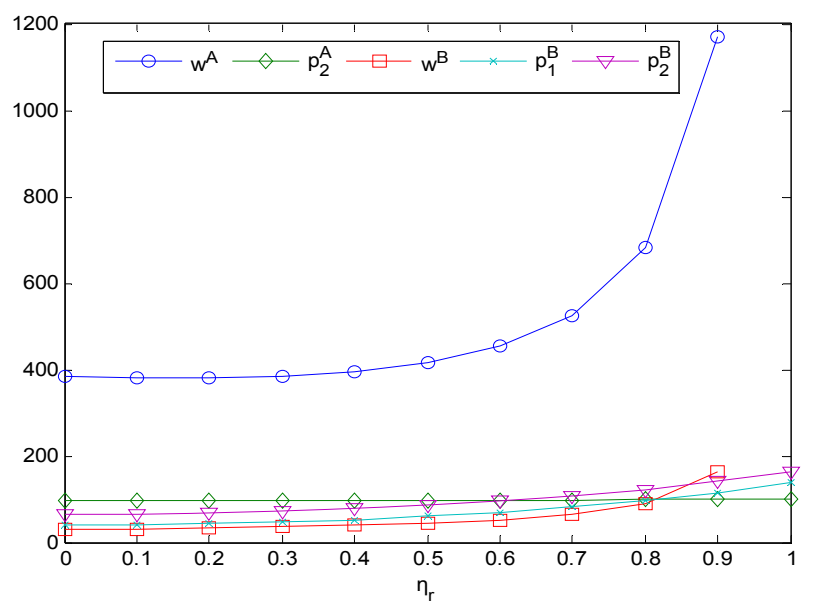

Figure 4. Impact of the retailer's altruistic preference on the player's pricing strategy.

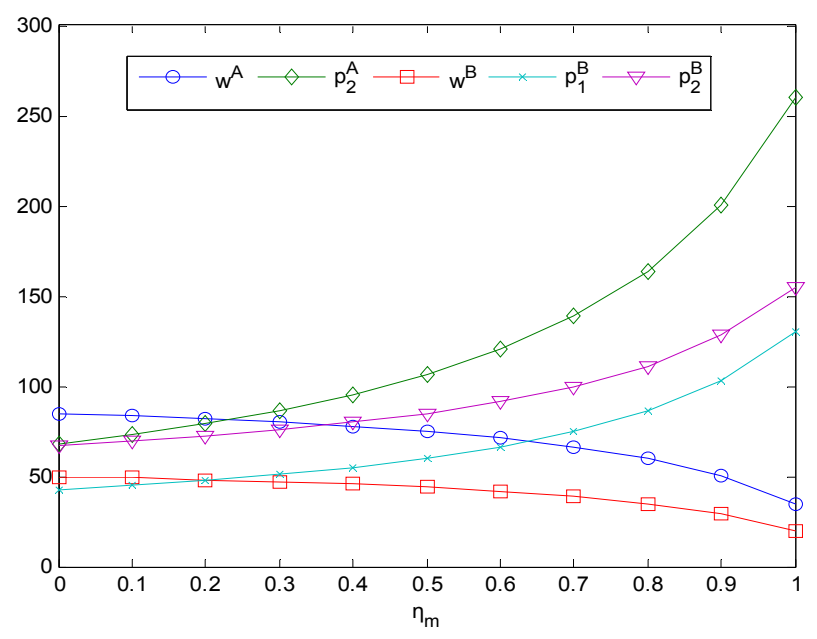

Figure 5. Impact of the manufacturer's altruistic preference on each player's pricing strategy.

preference on each player's pricing strategies.

In Figure 4, all the price increase with increasing $\eta_{r}$, in which the effect of retailer's altruistic preference on wholesale price is much more obvious, and the effect on the other prices is less observable. That means, the more altruistic the retailer is, the higher wholesale price the manufacturer set. The manufacturer benefits from the retailer's increasing altruistic preference or say the manufacturer use the retailer's altruistic preference to obtain more profit by increasing wholesale price. In addition, the effect of retailer's altruistic preference on wholesale price in supply chain (a) is greater than that in supply chain (b). It's because the manufacturer in supply chain (a) is more powerful as he controls both wholesale price and direct price while he is less powerful in supply chain (b) where he only control the wholesale price, which also explains why wholesale price in supply chain $B$ is lower than that in supply chain (a).

From Figure 5, we clearly see that wholesale prices in both supply chains (a) and (b) are decreasing with increasing $\eta_{m}$, while the online price and traditional price are increasing. The more altruistic the manufacturer is, the lower the wholesale price is set. That means, altruistic manufacturer transfers some part of his profit to retailer by reducing wholesale price as he shows concerns about the retailer's well-being (note that wholesale price in supply chain B is also lower than that in supply chain (a), just as in Figure 4). The retailer benefits from the manufacturer's increasing altruistic preference or say the retailer use the manufacturer's altruistic preference to obtain more profit by increasing traditional and online price. Comparing Figures $\mathbf{4}$ and 5, we see that the effect of the manufacturer's altruistic preference on the two dualchannel supply chains is more obvious than that of the retailer's altruistic preference. Moreover, the optimal prices in supply chain (a) are higher than those in supply chain (b).

In this paper, we develop a framework to study the effect of altruistic preference in two classic dual-channel supply chains. The results show that altruism strongly influences the retailer's and manufacturer's pricing strategies. Numerical studies reveal that the product webfit also has great effect on optimal pricing strategies.

We obtain some new results differing from those in previous literature. Study shows that altruism greatly affects each player's pricing strategies. The more altruistic a player is, the more profitable the other player is. Specifically, one player benefits from the other player's altruistic preference. In addition, we found that the manufacturer's altruistic preference influences each player's pricing strategies more greatly than the retailer's altruistic preference. In a dual-channel supply chain, online price is always lower than traditional price, which also holds true when the retailer and the manufacturer are altruistic according to our study. Analysis reveals that product web-fit affects each player's pricing strategies. The more compatible with the online channel the product is, the lower the retail price is set, the more profitable for the manufacturer and less profitable for the retailer. From numerical examples, we see that the optimal prices in supply chain (a) are set higher than the corresponding prices in supply chain (b).

There are several directions for future research that will achieve a better understanding of dual channel supply chain. For instance, it is assumed that all information is known to the retailer and the manufacturer, and thus, it is insightful to consider asymmetric information, which may change the interaction between the players. In addition, it would be interesting to examine conditions under which it would be more profitable when two channels compete with each other.

\section{Acknowledgements}

This research was supported in part by: 1) the National 
Natural Science Foundation of China under Grant 71071075 and 71173103 ; 2) the Major Program of National Social Science Foundation of China under Grant 12\&ZD204; and 3) the Humanities and Social Science Foundation (10YJA790183, 12YJC630180) of the Ministry of Education, China.

\section{REFERENCES}

[1] W. Chiang, D. Chhajed and J. Hess, "Direct Marketing, Indirect Profits: A Strategic Analysis of Dual-Channel Supply Chain Design," Management Science, Vol. 29, No. 1, 2003, pp. 1-20. doi:10.1287/mnsc.49.1.1.12749

[2] G. E. Fruchter and C. S. Tapiero, "Dynamic Online and Offline Channel Pricing for Heterogeneous Customers in Virtual Acceptance," International Game Theory Review, Vol. 7, No. 2, 2005, pp. 137-150. doi:10.1142/S0219198905000454

[3] K. Cattani, W. Gilland, H. S. Heese and J. M. Swaminathan, "Boiling Frogs: Pricing Strategies for a Manufacturer Adding a Direct Channel that Competes with the Traditional Channel," Production and Operations Management, Vol. 15, No. 1, 2006, pp. 40-56.

[4] W. Huang and J. M. Swaminathan, "Introduction of a Second Channel: Implications for Pricing and Profits," European Journal of Operational Research, Vol. 194, No. 1, 2009, pp. 258-279. doi:10.1016/j.ejor.2007.11.041

[5] J. Chen, H. Zhang and Y. Sun, "Implementing Coordination Contracts in a Manufacturer Stackelberg DualChannel Supply Chain," Omega, Vol. 40, No. 5, 2012, pp. 571-583. doi:10.1016/j.omega.2011.11.005

[6] S. Huang, C. Yang and X. Zhang, "Pricing and Production Decisions in Dual-Channel Supply Chains with Demand Disruptions," Computers \& Industrial Engineering, Vol. 62, No. 1, 2012, pp. 70-83. doi:10.1016/j.cie.2011.08.017

[7] W. Chiang and G. E. Monahan, "Managing Inventories in a Two-Echelon Dual-Channel Supply Chain," European Journal of Operational Research, Vol. 162, No. 3, 2005, pp. 25-41.

[8] M. Khouja and Y. L. Wang, "The Impact of Digital Channel Distribution on the Experience Goods Industry," European Journal of Operational Research, Vol. 207, No. 1, 2010, pp. 481-491. doi:10.1016/j.ejor.2010.04.007

[9] S. H. Chun, B. D. Rhee, S. Y. Park S Y and J. C. Kim, "Emerging Dual Channel System and Manufacturer's Direct Retail Channel Strategy," International Review of Economics and Finance, Vol. 20, No. 4, 2011, pp. 812825. doi:10.1016/j.iref.2011.02.006

[10] B. Dan, G. Y. Xu and C. Liu, "Pricing Policies in a Dual-Channel Supply Chain with Retail Services," International Journal of Production Economics, Vol. 139, No. 1, 2012, pp. 312-320. doi:10.1016/j.ijpe.2012.05.014

[11] A. A. Tsay and N. Agrawal, "Channel Conflict and Coordination in the E-Commerce Age," Production and Operations Management, Vol. 13, No. 1, 2004, pp. 93-110. doi:10.1111/j.1937-5956.2004.tb00147.x

[12] M. Khouja, S. Park and G. Cai, "Channel Selection and
Pricing in the Presence of Retail-Captive Consumers," International Journal of Production Economics, Vol. 125, No. 1, 2010, pp. 84-95.

[13] G. Cai, "Channel Selection and Coordination in DualChannel Supply Chains," Journal of Retailing, Vol. 86, No. 1, 2010, pp. 22-36. doi:10.1016/j.jretai.2009.11.002

[14] D. Q. Yao and J. J. Liu, "Competitive Pricing of Mixed Retail and E-Tail Distribution Channels," Omega, Vol. 33, No. 1, 2005, pp. 235-247. doi:10.1016/j.omega.2004.04.007

[15] P. D. Berger, J. Lee and B. D. Weinberg, "Optimal Cooperative Advertising Integration Strategy for Organizations Adding a Direct Online Channel," Journal of the Operational Research Society, Vol. 57, No. 8, 2006, pp. 920 927. doi:10.1057/palgrave.jors.2602069

[16] S. K. Mukhopadhyay, X, Zhu and X. Yue, "Optimal Contract Design for Mixed Channels under Information Asymmetry," Production and Operations Management, Vol.17, No. 6, 2008, pp. 641-650.

doi:10.3401/poms.1080.0069

[17] K. Y. Chen, M. Kaya and O. Ozer, "Dual Sales Channel Management with Service Competition," Manufacturing \& Service Operations Management, Vol. 10, No. 4, 2008, pp. 654-675. doi:10.1287/msom.1070.0177

[18] G. Hua, S. Y. Wang and T. C. Cheng, "Price and Lead Time Decisions in Dual-Channel Supply Chains," European Journal of Operational Research, Vol. 205, No. 1, 2010, pp. 113-126. doi:10.1016/j.ejor.2009.12.012

[19] R. Yan and Z. Pei, "Information Asymmetry, Pricing Strategy and Firm's Performance in the RetailerMulti-Channel Manufacturer Supply Chain," Journal of Business Research, Vol. 64, No. 4, 2011, pp. 377-384. doi:10.1016/j.jbusres.2010.11.006

[20] R. Lal and M. Sarvay, "When and How Is the Internet Likely to Decrease Price Competition?" Marketing Science, Vol. 18, No. 4, 1999, pp. 485-503. doi: $10.1287 / \mathrm{mksc} .18 .4 .485$

[21] J. Kacen, J. Hess and W. Chiang, "Bricks or Clicks? Consumer Attitudes toward Traditional Stores and Online Stores," Working Paper, University of Illinois, 2002.

[22] P. Korgaonkar, R. Silverblatt and T. Girard, "Online Retailing, Product Classifications, and Consumer Preferences," Internet Research, Vol. 4, No. 3, 2006, pp. 289323.

[23] T. H. Cui, J. S. Raju and Z. J. Zhang, "Fairness and Channel Coordination," Management Science, Vol. 53, No. 8, 2007, pp. 1303-1314. doi:10.1287/mnsc.1060.0697

[24] H. Loch and Y. Wu, "Social Preferences and Supply Chain Performance: An Experimental Study," Management Science, Vol. 54, No. 11, 2008, pp. 1835-1849. doi: $10.1287 / \mathrm{mnsc} .1080 .0910$

[25] M. Laeequddin, B. S. Sahay, V. Sahay and K. A. Waheed, "Measuring Trust in Supply Chain Partners' Relationships," Measuring Business Excellence, Vol. 14, No. 3, 2010, pp. 53-69. doi:10.1108/13683041011074218

[26] S. M. Disney and T. Hosoda, "Altruistic Behavior in a Two-Echelon Supply Chain with Unmatched Proportional Feedback Controllers," International Journal of Intelli- 
gent Systems Technologies and Applications, Vol. 6, No. 3, 2009, pp. 269-286. doi:10.1504/IJISTA.2009.024257

[27] Z. H. Ge, Q. Y. Hu, "Who Benefits from Altruism in Supply Chain Management?" American Journal of Operational Research, Vol. 2, No. 2, 2012, pp. 59-72. doi:10.4236/ajor.2012.21007

[28] R. C. King, R. Sen and M. Xia, "Impact of Web-Based E-Commerce on Channel Strategy in Retailing," International Journal of Electronic Commerce, Vol. 8, No. 3, 2004, pp. 103-130.
[29] R.Yan, J. Wang and B. Zhou, "Channel Integration and Profit Sharing in the Dynamics of Multi-channel Firms," Journal of Retailing and Consumer Services, Vol. 17, No. 1, 2010, pp. 430-440. doi:10.1016/j.jretconser.2010.04.004

[30] G. Charness and M. Rabin, "Understanding Social Preferences with Simple Tests," The Quarterly Journal of Economics, Vol. 117, No. 3, 2002, pp. 817-869. doi: $10.1162 / 003355302760193904$ 


\section{Appendix}

\section{Proof of Proposition 1}

Taking the second-order partial derivatives of $\pi_{c}$ with respect to $p_{1}$ and $p_{2}$, we have the Hessian matrix

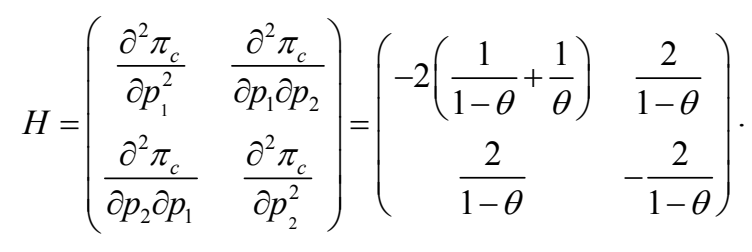

Since

$$
\frac{\partial^{2} \pi_{c}}{\partial p_{1}^{2}}<0
$$

and

$$
\left|\begin{array}{cc}
-2\left(\frac{1}{1-\theta}+\frac{1}{\theta}\right) & \frac{2}{1-\theta} \\
\frac{2}{1-\theta} & -\frac{2}{1-\theta}
\end{array}\right|>0
$$

$\pi_{c}$ is strictly jointly concave in $p_{1}$ and $p_{2}$. So the optimal solution exists. Then let the first-order condition equal to zero, we derive Proposition 1.

\section{Proof of Proposition 2}

Taking the second-order partial derivatives of $\pi_{r}^{A}$ with respect to $p_{2}$, we have

$$
\frac{\partial \pi_{r}^{2}}{\partial p_{2}^{2}}=-\frac{2}{1-\theta}<0 .
$$

Then let the first-order partial derivative of $\pi_{r}^{A}$ with respect to $p_{2}$ be zero, we have

$$
p_{2}=\frac{(1-\theta) v+p_{1}+w}{2}
$$

then substitute it into (10), and $\pi_{m}^{A}$ becomes a joint function of $p_{1}$ and $w$. We can easily obtain the optimal solution by analyzing Hessian matrix and the firstorder condition.

\section{Proof of Proposition 3}

Taking the second-order partial derivatives of $\pi_{r}^{B}$ with respect to $p_{1}$ and $p_{2}$, we have the Hessian matrix

$$
H=\left(\begin{array}{cc}
\frac{\partial^{2} \pi_{r}^{B}}{\partial p_{1}^{2}} & \frac{\partial^{2} \pi_{r}^{B}}{\partial p_{1} \partial p_{2}} \\
\frac{\partial^{2} \pi_{r}^{B}}{\partial p_{2} \partial p_{1}} & \frac{\partial^{2} \pi_{r}^{B}}{\partial p_{2}^{2}}
\end{array}\right)=\left(\begin{array}{cc}
-2\left(\frac{1}{1-\theta}+\frac{1}{\theta}\right) & \frac{2}{1-\theta} \\
\frac{2}{1-\theta} & -\frac{2}{1-\theta}
\end{array}\right) .
$$

Since

$$
\frac{\partial^{2} \pi_{c}}{\partial p_{1}^{2}}<0
$$

and

$$
\left|\begin{array}{cc}
-2\left(\frac{1}{1-\theta}+\frac{1}{\theta}\right) & \frac{2}{1-\theta} \\
\frac{2}{1-\theta} & -\frac{2}{1-\theta}
\end{array}\right|>0
$$

$\pi_{c}$ is strictly jointly concave in $p_{1}$ and $p_{2}$. So the optimal solution exists. Then let the first-order conditions equal to zero, we derive

$$
p_{1}=\frac{w+\theta v}{2}, \quad p_{2}=\frac{w+v}{2} .
$$

Substituting them into (12), and letting the first-order condition of $w$ be zero, we have

$$
w=\frac{c+\theta v}{2},
$$

and then Proposition 3 is proved.

\section{Proof of Proposition 4}

The proof of Proposition 4 is similar to Proposition 2, so we omit it.

\section{Proof of proposition 5}

The proof of Proposition 5 is similar toProposition 3, so we omit it. 